\title{
Experimental Study on Penetration of Small Caliber Ammunition into Different Multilayer Compact Armors
}

\author{
Y. A. Abo El Amaim*, A. I. Fayed ${ }^{\dagger}$, T. F. Khalifa ${ }^{\ddagger}$ A. A. Salman ${ }^{\S}$
}

\begin{abstract}
Nowadays Lightweight armor is very important and used in many applications. Through this study, Penetration behavior was studied through two different types of armors. The first one produced was lightweight composite armor with reducing the number of layers to less than 25 layers of Kevlar using polyurethane rubber resin with high impact and tenacity properties, while the second produced type was a multilayer armor with less than 25 layers of aramid but without using resin Line-x coating in the back. The hand lay-up technique was used for the first type, while the second type was produced by stitching the back layers. Samples were tested for their properties and its ability to defeat $9 \mathrm{~mm}$ bullets in protection level IIIA according to NIJ standards. Afterwards the behavior of the small caliber into the two types by the post firing examination tests were studied, where the results resulted in (no penetration) for the two types and complete protection with very lightweight and very thin armor with different reaction of trauma.
\end{abstract}

Keywords: Composites- ballistic - lightweight armor - Kevlar and Aramids

\section{Introduction}

The objective of making ballistic armor is to reduce the speed of the projectile to zero velocity while minimizing trauma. ${ }^{(1)}$ The kinetic energy transferred to a fabric target is composed of in-plane motion of the material outside the deformation cone in the wake of the strain wave front, and the out-of-plane motion of the yarns in the deformation cone. The kinetic energy of a fabric system is affected by the mass (or areal density) of the target, and the volume of the material in motion. As with the strain energy, the kinetic energy can also be affected by the boundary conditions imposed on the target. ${ }^{(2)}$

The strain energy and kinetic energy of all the yarns in deformed region are analyzed at the unconstrained and constrained stat. The energy absorbed by all yarns in rhombic region when fabrics are deformed into tetrahedron shape under ballistic impact, and especially the mechanical properties of yarn at high strain rate, are taken into consideration. The determination of failure criterion is based on maximum strain criterion. From the energy conservation law, the residual kinetic energy of projectile after ballistic impact could be obtained. The residual velocity and the decrease of kinetic energy of projectile, in experimental and theoretical, are all in agreement. It proves that the analytical model is correct and valid in prediction.

Faculty of Technical Education, Beni Suef University; engsamaim2000@ @otmail.com

Egyptian Armed Forces, Egypt; amr.fayed@mtc.edu.eg .

Faculty of Applied Arts, Helwan University, Egypt

Faculty of Applied Arts, Helwan University, Egypt 
Relative velocity, shape of colliding objects, relative stiffness and masses, location of contact, dimensions and boundary conditions, material characteristics, etc are very important parameters which caused the complexity of impact problems. ${ }^{(3)}$

Fibers are excellent reinforcing materials for polymers. When a small amount of polymeric resin is added to the fibers or fabrics, they form a reasonably stiff composite material which can be shaped into certain fixed forms such as helmets as protection against fragments from exploding ammunitions. In addition, they are lighter than steel due to the low density of both fibers and polymeric resins and the excellent axial properties of fibers ${ }^{(4)}$.

Kevlar is an aramid fiber. It has high energy absorption during failure, which makes it ideal for impact and ballistic protection. It also had low density, high strength-to-weight ratio, and high modulus-to-weight ratio. So, it is always used in body armors. (5)

The polyurethane resins are widely available in the industry for multiple uses due to their toughness, flexibility in terms of resin elongation at failure, bond strength between different substrates, high pigment loading, exceptional bonding with rubber and metals, high breaking and tearing strength when used as thin tapes loaded with magnetic oxide binder for magnetic tape, toughened and high abrasive properties, good electric wire and application ease in electrical systems. ${ }^{(1)}$

Usually Kevlar isn't used with resin because resin affects badly on fibers of Kevlar and makes it weak and reduce its tenacity that reduces the efficiency of armor against bullets. So Kevlar is used without resin and layers of Kevlar are collected by stitching. In this present work we tried to use Kevlar with polyurethane rubber which has good impact ability by using different procedures to production.

(Tan and Khoo) $^{(6)}$ investigated the response of flexible composite laminates to ballistic impacts by projectiles of various nose shape; these were: flat-ended, hemispherical, oval and conical $\left(30^{\circ}\right.$ half-angle) nose shapes. It was recognized at a very early stage that the plain weave was the most efficient in dissipating impact energy because the simple weave introduces the most cross-yarn interactions. The yarn crossover points facilitated the dissipation of impact energy to yarns not in direct contact with the projectile. They conducted ballistic tests using four types of projectiles over a range of impact velocities up to $400 \mathrm{~m} / \mathrm{s}$. The Spectra Shield plates were clamped along top and bottom edges while other two edges were free.

(El Gamhoudy) ${ }^{(7)}$ predicted the Ballistic impact resistance of textile and composite targets is successfully using the suitable analytical model which is based on wave theory and energy balance between projectile and target. And by using A MATLAB program is described the penetration process due to the impact of a small caliber projectile into textile and composite targets, respectively. This program calculates different energies absorbed during ballistic impact, projectile displacement into a target and the residual velocity.

\section{Experimental Work}

\subsection{Materials}

Samples were fabricated from multilayers of plain weave of Kevlar 129 with yarn count 1100 detex, the number of layers is less than 25 layers, and these layers were laminated with polyurethane rubber which has good impact and tensile properties from AP\&C company- 
Egypt. Polyurethane rubber resin is a two-component (polyol and isocynate) having high flexibility ${ }^{(7)}$. It is fast cure for service at ambient temperature after 24 hours under press. It has low density and relatively high abrasion resistance, impact strength, tensile strength, high resistance to severe weather conditions.

LINE-X XS-350 is a two-component spray-in-place, flexible $100 \%$ solids Polyuria/Polyurethane system. It is designed for processing through LINE-X dispensing equipment. It is fast cure for service at ambient temperature after 24 hours. It has low density and relatively high abrasion resistance, impact strength, tensile strength, high resistance to severe weather conditions, and high elongation percent, flexible polymer (line-x) also was chosen to produce composite materials with known construction from E-glass and polymers (8).

The two types of armors are shown in the following Table (1).

(Kp-1) First type manufactured using polyurethane rubber resin.

(Kp-2) Second type of armors manufactured with stitching and line-X in the back.

Table (1) The armor two types

\begin{tabular}{|c|c|c|c|}
\hline $\begin{array}{c}\text { Sample } \\
\text { Code }\end{array}$ & Elevation of sample & Side view of the sample \\
\hline KP-1 & & & \\
\hline KP-2 & & & \\
\hline
\end{tabular}




\subsection{Methods}

The sample of the first type Kevlar composite armor was made by hand lay-up process, resin of polyurethane rubber consisting of two components were applied and the curing time was less than 30 minutes.

Within 25 minutes the sample was made by hand lay-up process after that the sample was placed under pressure for $24 \mathrm{hr}$., Figure (1) shows the production process.

The second type of the armor was manufactured by stitching and coating the back layers with Line-X through gun spray. Figure (2) shows dispensing equipment, two components barrels and the compressor.

Samples were then tested to determine its weight and thickness and ballistic test and the tests of tensile strength and tear strength for the Kevlar fabric were held.
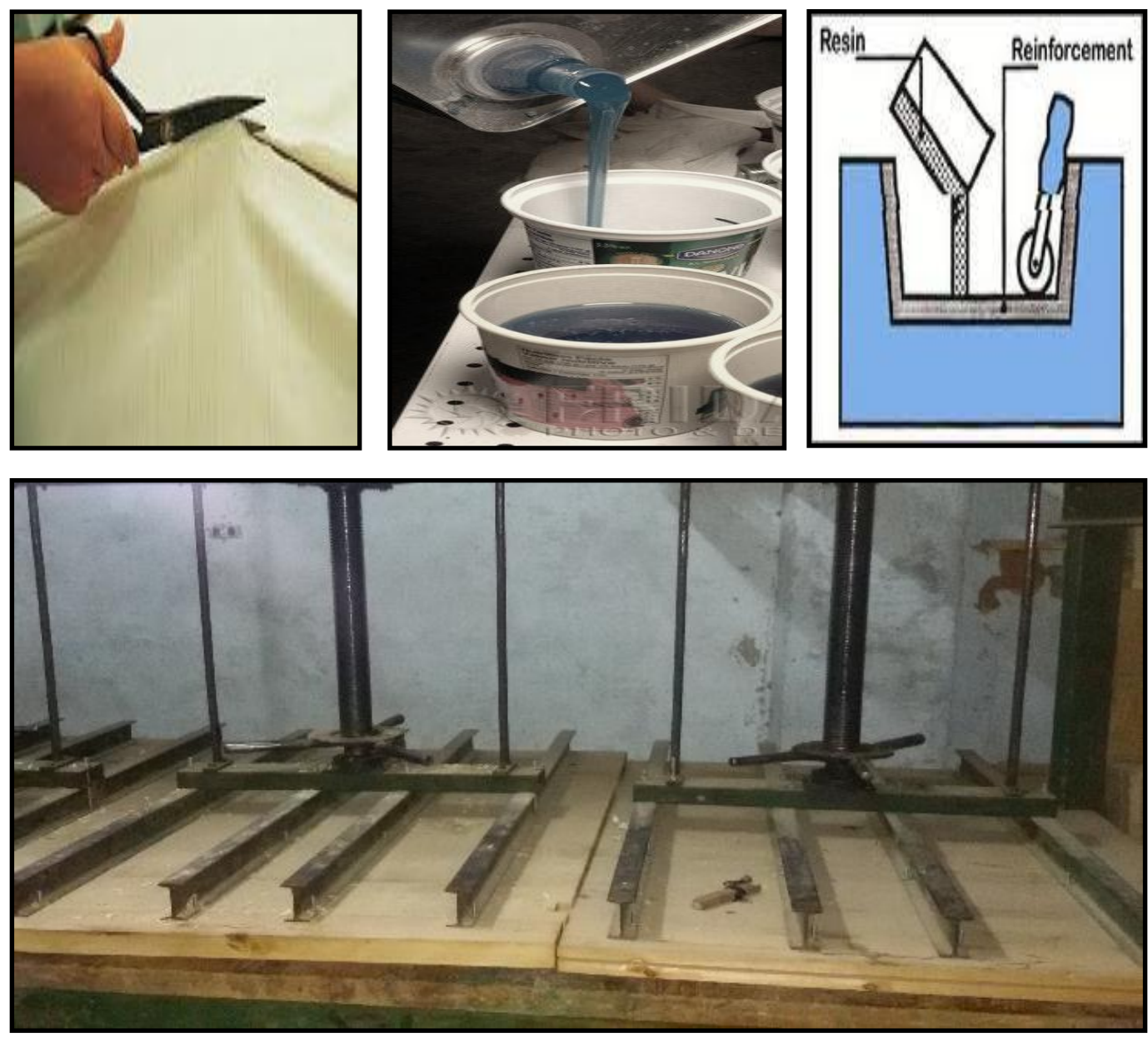

Fig. (1) Making process (cutting samples, polymer preparing, hand lay-up then placing the sample under the pressure) 


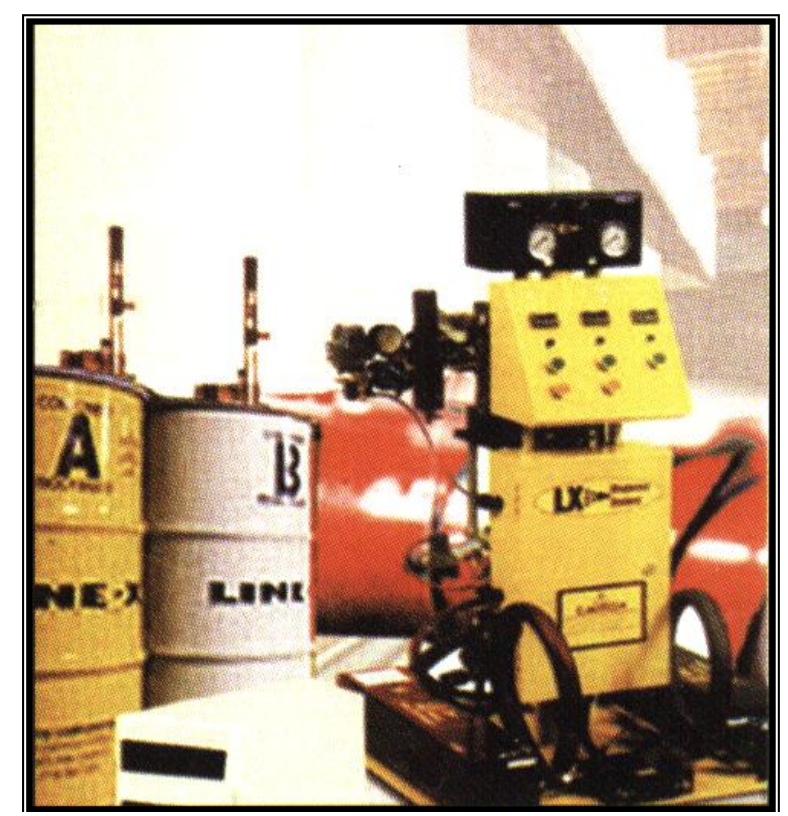

Fig. (2) LINE-X dispensing equipment and two components barrels

\subsection{Ballistic Test}

The test was applied according to standard; some sample were tested at level IIIA ( $400 \mathrm{~m} / \mathrm{sec}$ $\pm 10)$ according to NIJ standard ${ }^{(9)}$

\subsubsection{Test set up}

Preparing of the backing material from clay and set up the rifle for shooting, then we shoot on the samples by small caliber its weight is 8 gram and its velocity is $400 \mathrm{~m} / \mathrm{sec}$ from 5 meters, figure (3) shows the rifle and figure (4) shows the test setup.

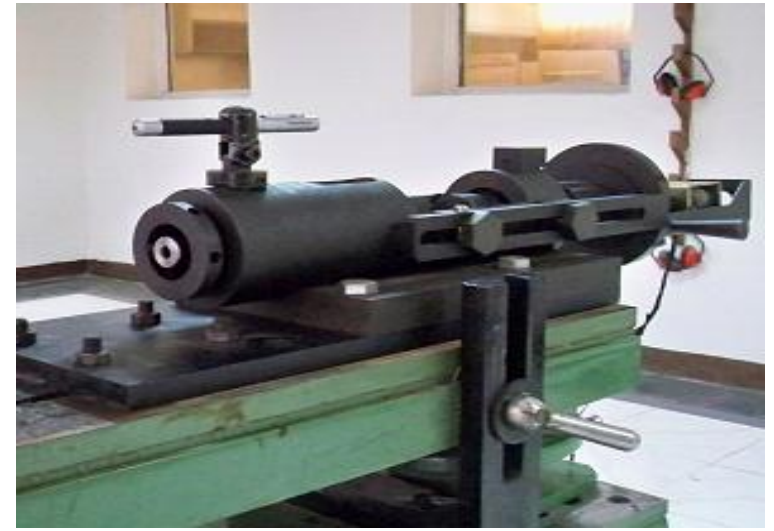

Fig. (3) HPI Ballistic rifle of caliber 9 mm and its mount

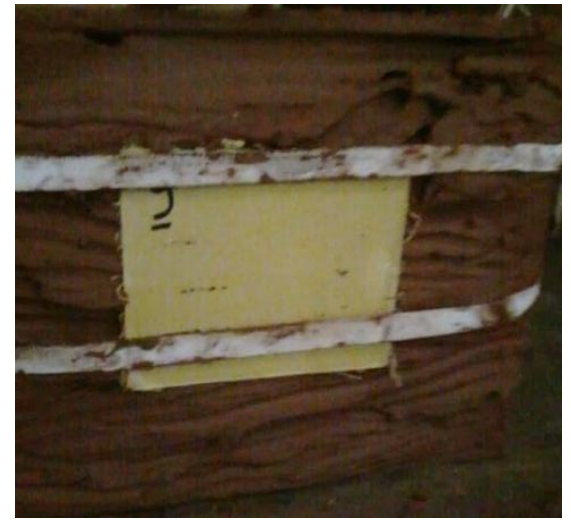

Fig. (4) the test set up 


\section{3. Results and discussion}

The results of tensile strength and tear strength ${ }^{(10)}$ of the Kevlar fabric which used to manufacture the two types of samples of armors as the following table (2):

Table (2) Kevlar sample properties

\begin{tabular}{|c|c|c|c|c|c|c|}
\hline \multirow{2}{*}{ Sample } & Weight & Thickness & \multicolumn{2}{|c|}{ load (N) } & \multicolumn{2}{c|}{ Tearing load (N) } \\
\cline { 4 - 7 } & g/m & Mm & Warp & Weft & Warp & Weft \\
\hline Kevlar & 120 & 0.30 & 5293 & 5213 & 1640 & 1780 \\
\hline
\end{tabular}

Figure (5) illustrates kevlar fabric sample before and after tensile strength test.

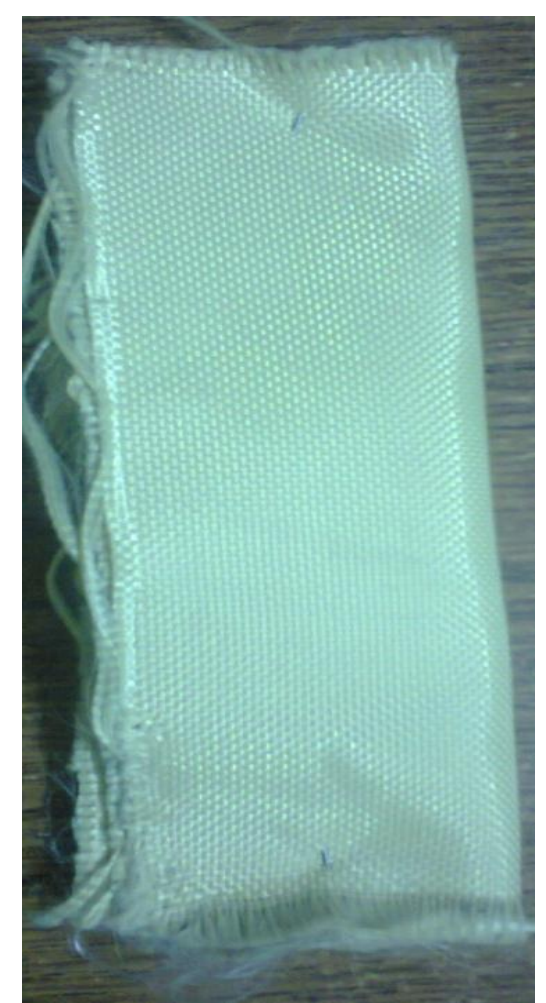

A: Before test

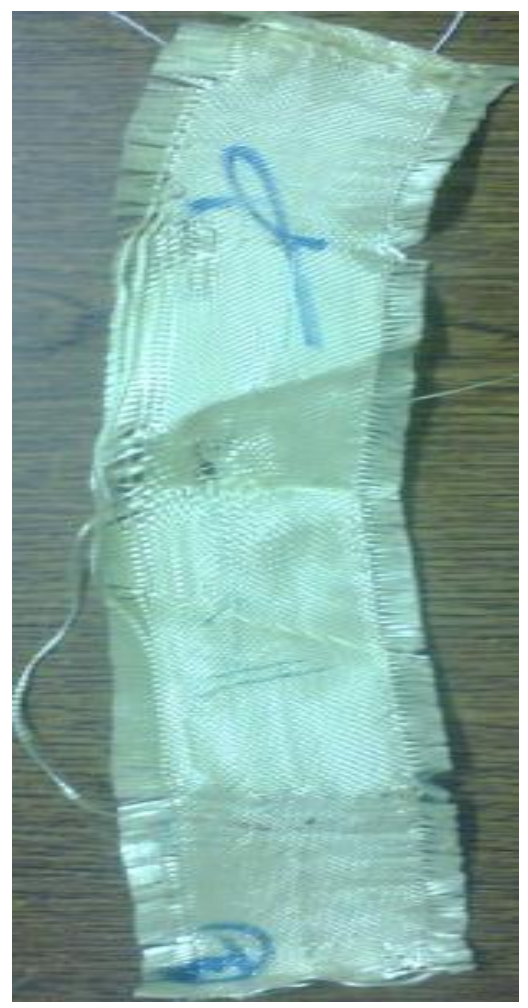

B: After test

Fig. (5) Kevalr fabric sample before and after tensile stenghth test

In this study the properties of two samples of composite Kevlar -polyurethane rubber are measured (weight, thickness, ballistic impact resistance by shooting $9 \mathrm{~mm}$ caliber on 5 meters distance) table (3) shows the results of tests of measuring the sample's properties.

Table (3) Sample properties

\begin{tabular}{|c|c|c|c|c|c|c|}
\hline No & $\begin{array}{c}\text { Sample } \\
\text { Code }\end{array}$ & $\begin{array}{c}\text { Weight } \\
\mathbf{k g} / \mathbf{m}^{\mathbf{2}}\end{array}$ & $\begin{array}{c}\text { Thickness } \\
\mathbf{m m}\end{array}$ & $\begin{array}{c}\text { Impact } \\
\text { Velocity } \mathbf{~ m / s e c}\end{array}$ & $\begin{array}{c}\text { Penetration } \\
\text { ratio \% }\end{array}$ & $\begin{array}{c}\text { Trauma } \\
\text { value } \\
\mathbf{M m}\end{array}$ \\
\hline 1 & KP-1 & 8.750 & 7 & 400 & 55 & 18 \\
\hline 2 & KP-2 & 9.250 & 9 & 400 & 50 & 5 \\
\hline
\end{tabular}

And the ballistic test results are shown as the following: 
Table (4) Ballistic test results

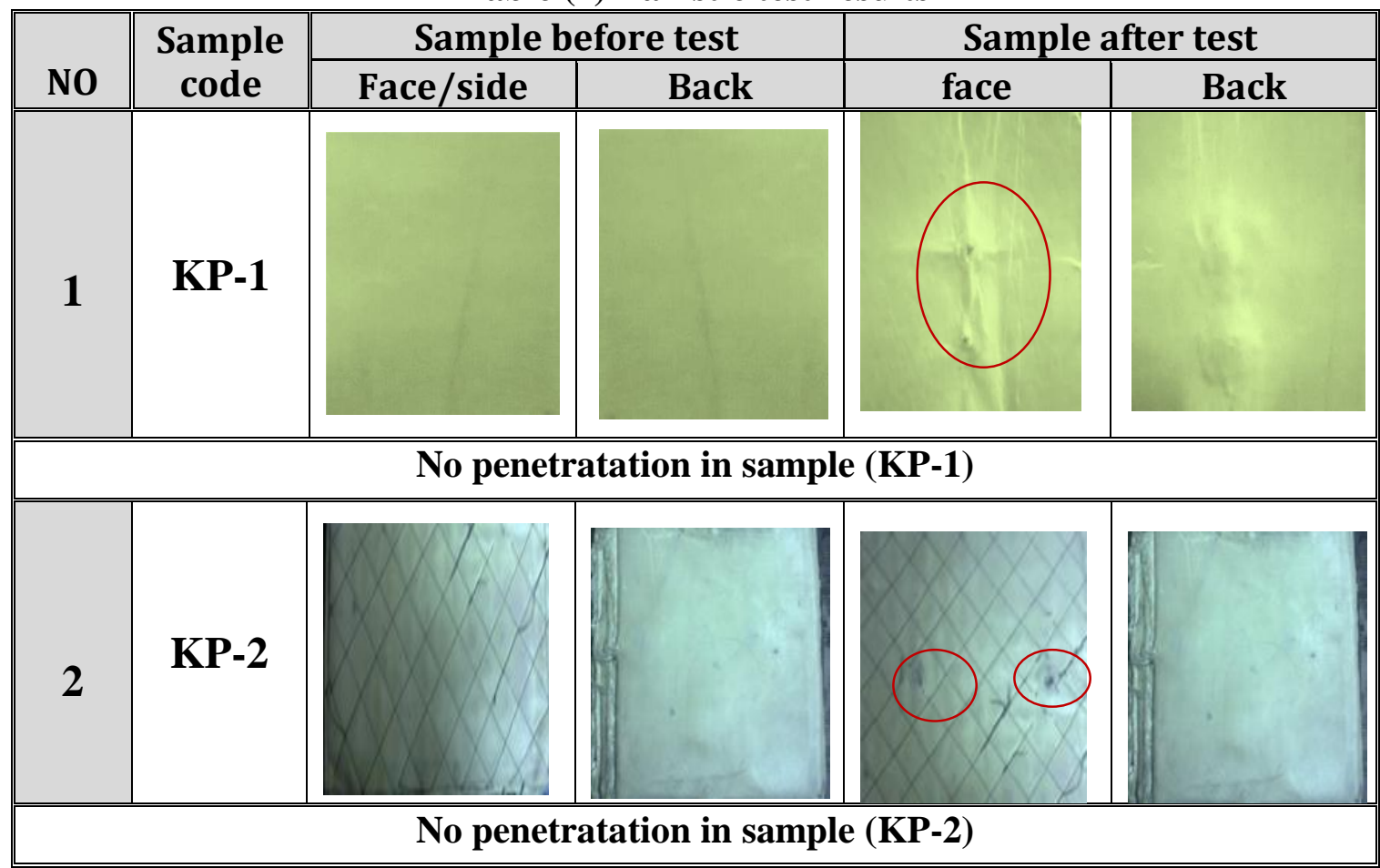

- Sample (KP-1) was not penetrated and there was trauma $(18 \mathrm{~mm})$, sample is very thin and with low weight. It could be used in a lot of application.

- Sample (KP-2) was not penetrated and there was trauma (5 mm) Kevlar has different properties this sample is very thin and with low weight. It could be used in a lot of application

- Trauma is very small and fig (6) shows the trauma after impact test.

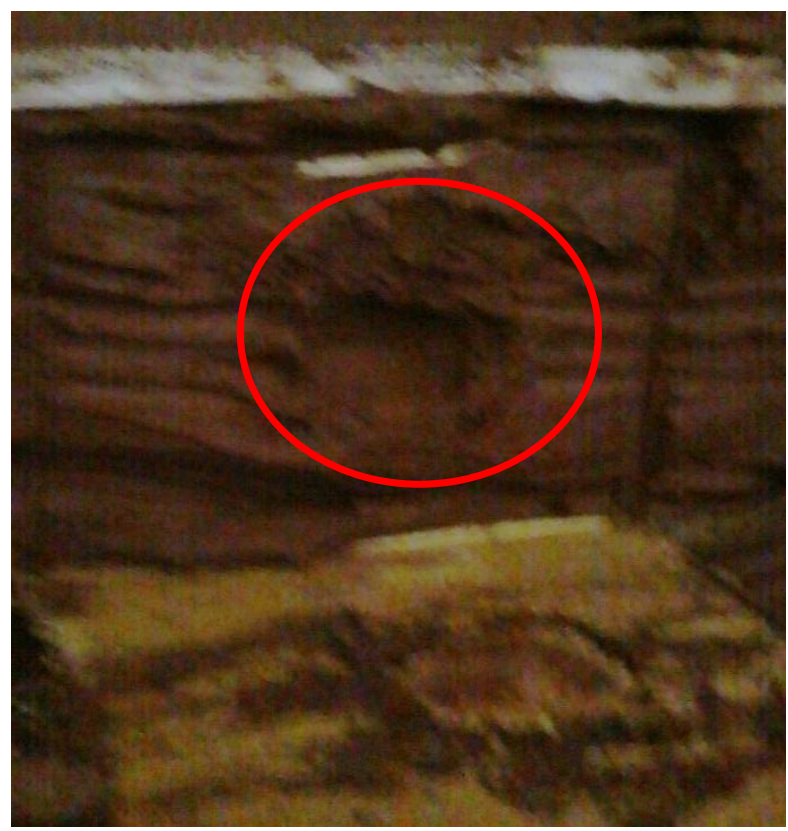

Fig. (6) Trauma of the impact test 


\subsection{Significant effect of the weight on the trauma}

There is significant relation between the fabric weight and trauma, statistically t tests= 4.171882 that mean by increasing the weight the trauma will be decreased.

Radar chart was used to assign the quality of each sample of the two types, where the two samples scored good results and very near as shown in the following figures

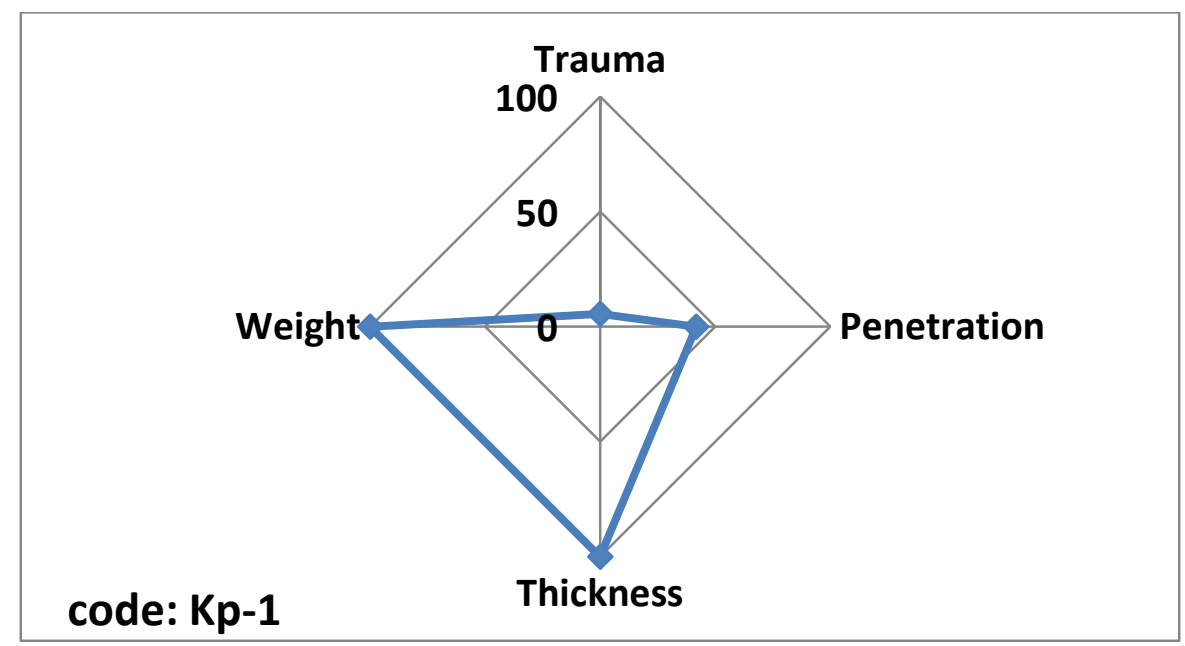

Fig. (7) Radar chart of performance quality of sample (KP-1)

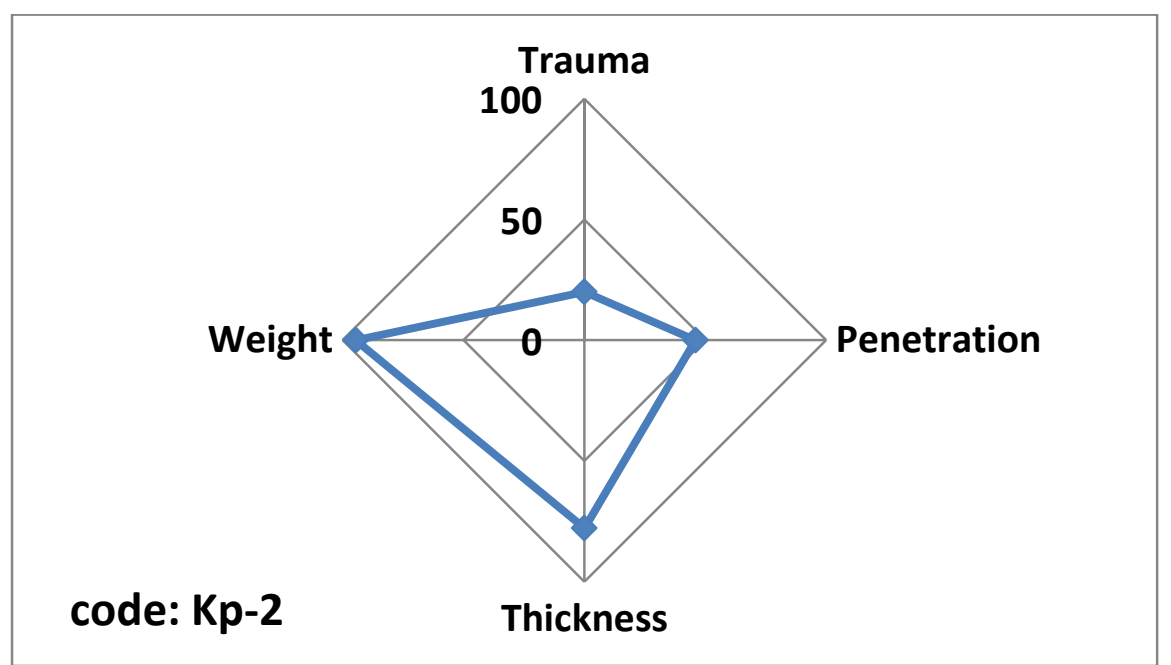

Fig. (8) Radar chart of performance quality of sample (Kp-2)

\section{Conclusion}

Using Flexible polymer coating (line-x) may give other results in case of increasing the number of layers which coated with it on stopping or opposing the penetration of the bullet in armors

Line- $\mathrm{X}$ is very good to decrease the trauma and by increasing the weight the trauma will be decreased

The trauma of the sample using Line- $x$ is less than the Trauma in the composite armor with resin. 
The results also showed that polyurethane rubber which has good impact property gave acceptable results with Kevlar and did not have bad effect its tenacity. The armor produced from the composite (multilayered Kevlar with polyurethane resin) was very lightweight, very thin thus reducing the number of layers and the cost of armor. In addition the armor can defeat small caliber in protection level IIIA according to NIJ standard. Therefore it can be applied in a lot of application as soft armors, vests, vehicles add on, shields and other many applications in protection.

\section{References}

[1] H. Annibal,"ballistic impact book light weight ballistic composites: Military and law enforcement application", Woodhead publishing, USA ,(2006).

[2] Cantwell,W.J.andJ.Morton(1990) 'Impact perforation of carbon fibre reinforced plastic,' Composites Science and Technology,38(2),119 \pm 141

[3] M.A.G. Silva, C. Cismaşiu , ,C.G. Chiorean, Numerical simulation of ballistic impact on composite laminates, International Journal of Impact Engineering, Volume 31, Issue 3, March 2005, Pages 289-306

[4] S. T. Peters, "Handbook of Composites", Process Research, Mountain View, California, USA, (1998).

[5] M.H. El Gamhoudy,"Ballistic resistance of laminated composites targets", master thesis, Military technical college, Cairo (2010).

[6] V.B.C.Tan, and K.J.L.Khoo, "Perforation of Flexible Laminates by Projectiles of Different Geometry", Int. J. Impact Engng, Vol. 31, pp.793-810(2005).

[7] Master thesis ,El Gamhoudy.M.A ,2010, Ballistic Resistance of Laminated Composite Targets,Military Technical College

[8] M. S. Abdelkader, A. I. Fayed and E. E. Elawad, "Penetration of Flexible Composite (Kevlar-129/Line-X XS 350)", 11th International Conf. on Aerospace Science \& Aviation Technology, 2005.

[9] NIJ Standards. United States Department of Justice, Ballistic Resistance of Body Armor NIJ Standard-0101.06".. July 2008.

[10] Tensile Strength Test-Grab Test, ASTM D 5034-95 (Reapproved 2001) 